\title{
Lack of research on efficacy of virtual reality exposure therapy (VRET) for anxiety disorders in children and adolescents
}

\section{A systematic review}

\author{
Oswald D. Kothgassner (D) A Anna Felnhofer (D)
}

Received: 31 January 2020 / Accepted: 13 April 2020 / Published online: 5 May 2020

(c) The Author(s) 2020

\begin{abstract}
Summary Anxiety disorders are one of the most prevalent mental disorders in children and adolescents which may effectively be treated by several forms of exposure therapy. An emerging approach to exposure is virtual reality exposure therapy (VRET), but a literature search synthesis focusing specifically on the use of VRET in children and adolescents is still lacking. This systematic review sets out to provide an overview concerning VRET for the treatment of anxiety disorders in this age group. Four published trials covering an overall sample of 100 participants between the ages of 8 and 16 years were found during a systematic literature search and were included in the current review. Results reveal that participants show clinical improvements regarding anxiety symptoms after VRET. Nevertheless, the high potential of virtual reality as a tool for treating children and adolescents with anxiety disorders is contrasted by a considerable lack of controlled trials. Despite the evidence of VRET in adult samples, there is a need for more research with younger cohorts in order to be able to support this promising field of application.
\end{abstract}

Keywords Virtual reality · Anxiety disorders · Specific phobia $\cdot$ Exposure treatment $\cdot$ Youth

\footnotetext{
Mag. Dr. O. D. Kothgassner $(\bowtie)$

Department of Child and Adolescent Psychiatry,

Medical University of Vienna, Waehringer

Guertel 18-20, 1090 Vienna, Austria

oswald.kothgassner@meduniwien.ac.at
}

\section{Mag. Dr. A. Felnhofer ( $₫)$}

Department of Pediatrics and Adolescent Medicine,

Medical University of Vienna, Waehringer

Guertel 18-20, 1090 Vienna, Austria

anna.felnhofer@meduniwien.ac.at

\section{Zur Wirksamkeit der Virtual Reality Expositionstherapie (VRET) von Angststörungen bei Kindern und Jugendlichen Ein systematischer Review}

Zusammenfassung Angststörungen gehören zu den häufigsten psychischen Störungen im Kindes- und Jugendalter, die durch verschiedene Formen der Expositionstherapie wirksam behandelt werden können. Ein neuer Ansatz zur Exposition ist die VRET (Virtual Reality Exposure Therapy), welche zunehmend in der Behandlung von Angststörungen gute Erfolge erzielt. Eine Aufarbeitung der Literatur dazu aus dem Kinder- und Jugendbereich ist allerdings noch ausstehend. Dieser systematische Review soll daher einen Überblick über die VRET als Behandlungsmethode für Angststörungen in dieser Altersgruppe geben. Vier veröffentlichte Studien, die insgesamt eine Stichprobe von 100 Teilnehmenden im Alter von 8-16 Jahren umfassen, wurden mithilfe einer systematischen Literaturrecherche identifiziert und in die hier vorgestellte Übersicht aufgenommen. Die Ergebnisse belegen, dass sich bei den Teilnehmenden nach VRET klinische Verbesserungen der Angstsymptome zeigen. Dem hohen Potenzial der virtuellen Realität als einem Instrument zur Behandlung von Kindern und Jugendlichen mit Angststörungen steht allerdings ein erheblicher Mangel an kontrollierten Studien gegenüber. Trotz der Evidenz für VRET in Erwachsenenstichproben besteht weiterer Forschungsbedarf mit jüngeren Kohorten, um dieses vielversprechende Anwendungsfeld unterstützen zu können.

Schlüsselwörter Virtuelle Realität · Angststörungen · Spezifische Phobie · Expositionsbehandlung · Jugend 


\section{Introduction}

Anxiety disorders are considered to be one of the most prevalent clusters of disorders in children and adolescents with a lifetime prevalence of $28.8 \%$ [12]. Recently, a school-based study in Austria [26, 28] revealed that the lifetime prevalence of anxiety disorders was up to $15.5 \%$, with an estimated prevalence of $7.3 \%$ for specific phobias (SPH), $3.5 \%$ for social anxiety disorders (SAD), and $1 \%$ for panic disorders (PD). Moreover, the prevalence was even higher in a population from mental health services, ranging between 9.5 and $16.0 \%$ for SPH, SAD and PD [26]. Another recent study on a mental hospital cohort in Austria reported that particularly female adolescents suffer more often from anxiety disorders [22].

Exposure therapy has been supported as a first-line evidence-based treatment for most anxiety disorders, like SPH, SAD, PD, as well as for posttraumatic stress disorders (PTSD), and obsessive-compulsive disorders (OCD) [3]. Accordingly, research indicates that exposure therapy can also be considered as a highly effective and efficacious treatment for children and adolescents with anxiety disorders [27]. This therapy approach sets out to-on the one hand-activate the phobic structure upon exposure to the feared stimulus, and to-on the other hand-achieve symptom reduction by habituation following repeated confrontation with the according stimulus (in vivo or in sensu) [8]. These two classical methods of exposure therapy, in vivo (exposure to a real stimulus) and in sensu (exposure to an imaginal stimulus), were amended by a technology-mediated form of exposure: virtual reality exposure therapy (VRET). In this approach, phobias are treated using a head-mounted device to present a computer-based feared virtual environment or a feared virtual stimulus. Recent studies [13, 29] show that exposure to a feared stimulus in virtual reality (VR) provokes levels of anxiety as well as physiological responses which are comparable to those induced by an exposure in vivo. Furthermore, experiences in VR influence emotional states and physiological responses in subsequent real-life interactions (e.g., subsequent emotional and physiological reactivity to real-life stressors; prolonged prosocial behavior) $[6,14,15]$. Additionally, there is a significant difference in the physiological activation between patients and healthy controls during exposure to a feared stimulus in VR (e.g., Felnhofer et al. [7]).

In sum, VRET is a valuable and effective treatment tool for anxiety disorders. It is also suggested by S3 guidelines as an evidence-based method particularly for specific phobias [4]. Accordingly, a recent meta-analysis by Carl et al. [5] including 30 randomized controlled trials (RCTs) supports the efficacy of VRET. The authors found that half of these studies compared VRET with cognitive behavioral therapy (CBT) -based in vivo exposure (IVE) revealing no dif- ferences in effect sizes between VRET and IVE. While these effects are especially true for SPH, SAD, and PD, another recent meta-analysis [16] showed that they could not be replicated for VRET in PTSD patients. In this paper, only 5 studies that compared VRET with an active comparator were identified. However, none of these active groups encompassed in vivo exposure or other first-line treatments as suggested by several guidelines (e.g., American Psychological Association [1]); hence, there is no clear evidence that VRET may also be effectively applied in PTSD patients. Apart from these limitations, the most recent meta-analyses on anxiety disorders $[5,16]$ did not include any trials focusing on VRET for SPH, SAD, PD, or PTSD in children or adolescents. All studies applied VRET only in adult patients. Hence, despite the large potential and efficacy of using VRET for the treatment of anxiety disorders (e.g., Carl et al. [5]), there is still a lack of systematic analyses of the current literature regarding the use of VRET in children and adolescents with anxiety disorders. Thus, this systematic review set out to provide a comprehensive overview of existing research on VRET for children and adolescents suffering from anxiety disorders including PTSD.

\section{Methods}

We selected trials from MEDLINE/PubMed and Google Scholar using the keywords 'VRET OR Virtual Reality Exposure Therapy AND anxiety disorders' in combination with terms 'therapy', 'treatment' and 'children' or 'adolescents' or 'youth'. Alternatively, we were searching for keywords 'VR OR Virtual Reality AND anxiety disorders' in combination with the above mentioned terms, as well as for 'VRET OR Virtual Reality Exposure Therapy AND phobia'; 'VRET OR Virtual Reality Exposure Therapy AND trauma'. We set the time range from the beginning of database records until January 2020. Studies were included if they reported at least one group with VR treatment. All control group interventions were included in the systematic review. However, all included studies were imposed with the restriction that all participants had to be less than 19 years of age. Feasibility studies lacking an overall evaluation of the treatment were registered and reported, but not included in the main analysis. Additionally, Google Scholar alerts were enabled to ensure inclusion of articles in press. Exclusion of documents occurred at each stage (see Fig. 1 for PRISMA flow diagram). Final inclusion and exclusion decisions were based on the following criteria:

- Participants: Individuals with an age less than 19 years of age and anxiety disorder/subclinical anxiety. Studies focusing on anxiety symptoms in developmental disorders, or autism spectrum disorder (ASD) were excluded due to comparison issues with isolated anxiety disorders. 
Fig. 1 PRISMA flowchart of screening, exclusion and inclusion criteria. VRET virtual reality exposure therapy, $A S D$ autism spectrum disorder

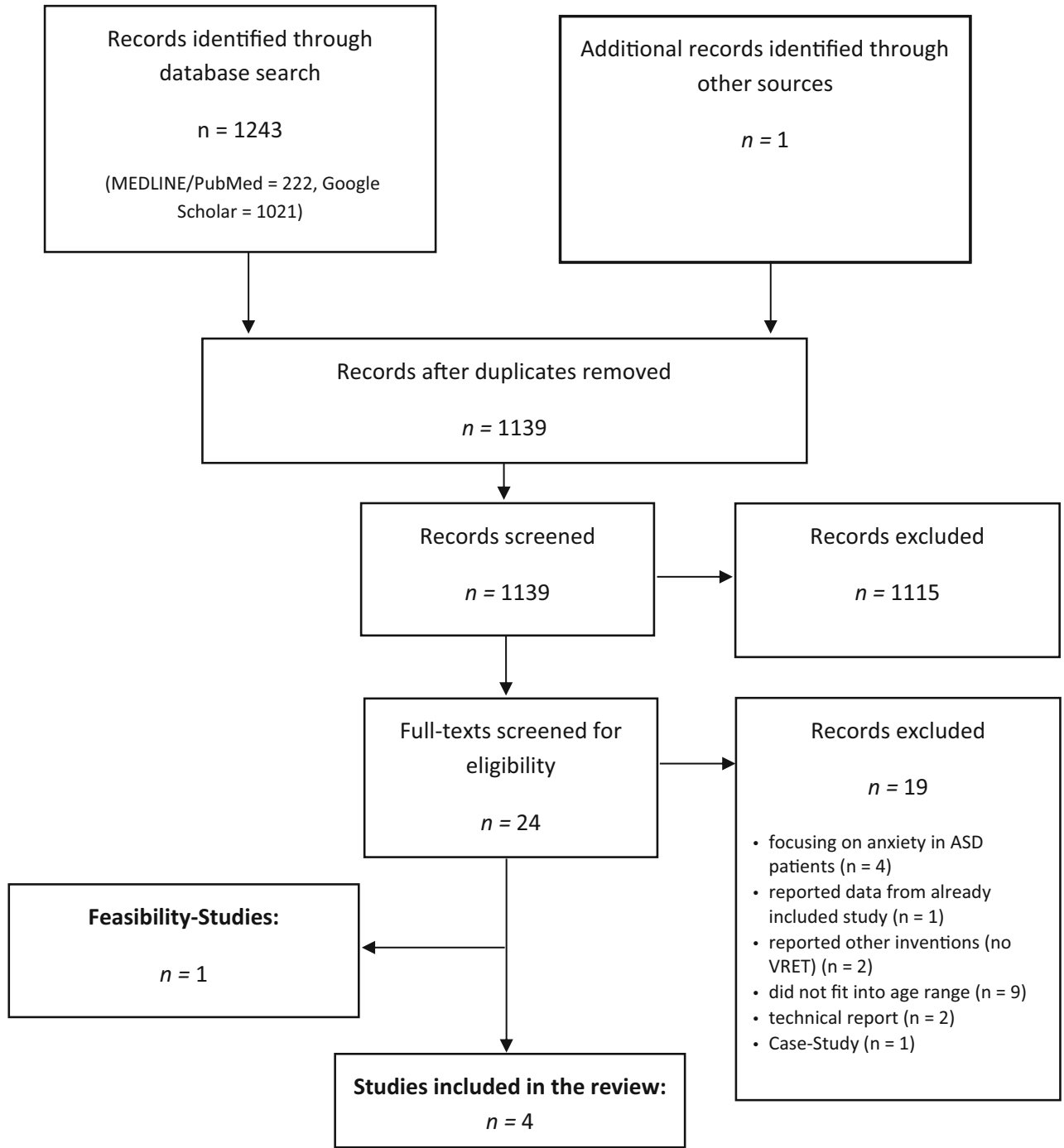

- Intervention: Virtual reality exposure therapy for anxiety disorders (SPH, SAD, PD, PTSD).

- Comparison: Studies with and without control groups were included. Therefore, pre-post evaluations or randomized controlled trials (RCTs) were included. Studies without an evaluation of the treatment effects per se were only reported as feasibility studies, but were not included in the main analysis.

- Outcomes: Studies reported at least a symptom severity score before and after the intervention.

The title, abstract, and manuscript of each study were examined by both authors independently. Risk of bias for each study based on the AHRQ Method Guide for Comparative Effectiveness Reviews [25] was assessed for each included study. Studies were rated according to categories regarding randomization, selection and attrition bias, confounding bias and measurement bias. Based on these predefined criteria, all studies were assessed with regard to low, moderate, or high risk of bias. We determined that inappropriate methods of randomization, not controlling for confounding factors such as high attrition $\geq 40 \%$ or differential loss $\geq 30 \%$ and problems in participant selection are reasons for high risk of bias ratings. Low risk of bias was predefined by appropriate randomization methods (e.g., computer-generated random allocation), low attrition $<20 \%$ or differential loss $<5 \%$, no significant baseline differences among groups regarding primary outcome measures and inclusion/ exclusion criteria, adequate control of confounders, use of validated assessments for outcome measures. Furthermore, we rated overall strength of evidence (SOE) according to Owens et al. [24] for all included studies as displayed in Table 1.

\section{Results}

The initial search following PRISMA Guidelines yielded 873 results. Titles and abstracts were screened for eligibility and full-text manuscripts were obtained (Fig. 1). After screening, $\mathrm{k}=4$ studies covering 100 participants (VRET-RCT: $n=35 /$ control conditions: $n=32$; pre-post evaluations: $n=33$ ) were identified 


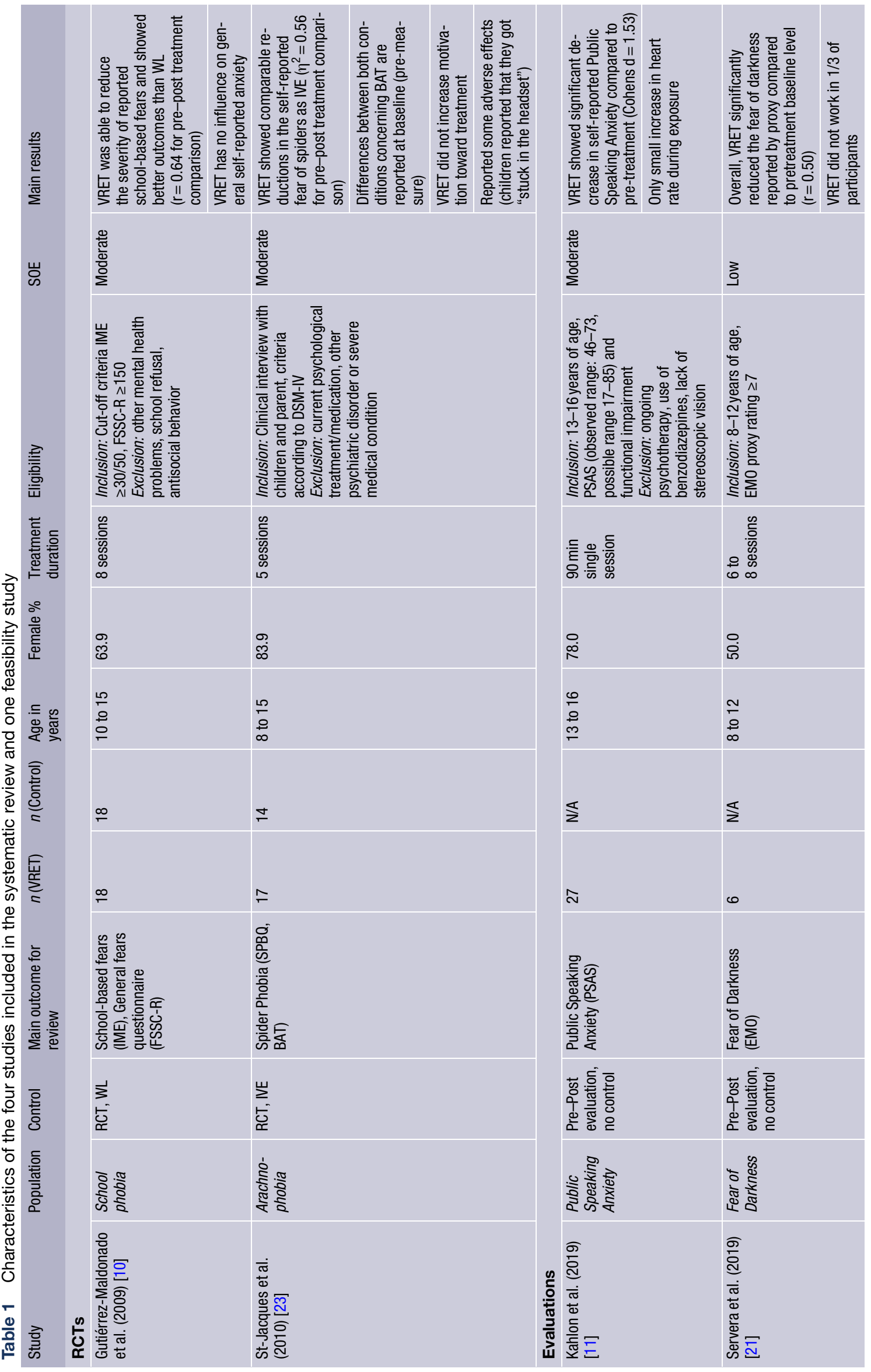




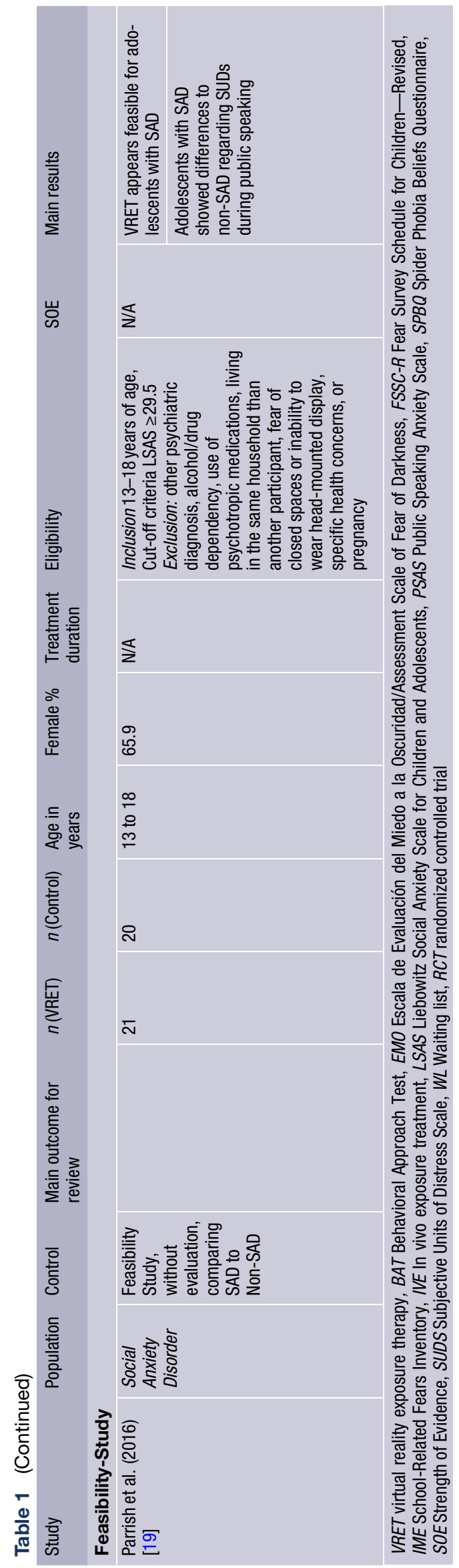

and included in the current review (see Table 1 for study characteristics). One feasibility study [19] was found without pre-post evaluation of the training. Our review suggests that both RCT studies [10, 23] showed moderate risk of bias. Pre-post evaluations showed low-moderate risk of bias. A detailed report about risk of bias in the specific domains of each study is presented in Fig. 2. Both RCTs reported an efficacy of VRET (Gutiérrez-Maldonado et al. [10] for School Phobia, St-Jacques et al. [23] for Arachnophobia). While Gutiérrez-Maldonado et al. [10] found a superior effect of VRET over a waitlist (WL) control group as assessed with self-report measures, the study by St-Jacques et al. [23] showed that the reported fear of spiders was reduced after VRET and IVE, but there was no differences between the two groups posttreatment. Both studies report large effect sizes concerning the effect of treatment. Kahlon et al. [11] and Servera et al. [21] both found large effect sizes for the significant differences between pretreatment and posttreatment measures regarding an improvement of self-reported public speaking anxiety symptoms as well as for fear of darkness levels reported by parents.

\section{Age and gender}

All studies reported a relatively broad age range covering 8 to 16 years of age. Most studies had a definite trend toward female gender, except for Servera et al. [21] who reported a 1:1 proportion, yet had a small sample $(n=6)$.

\section{Adverse effects}

Half of the included studies [11, 23] assessed the potential risk of simulator sickness. St-Jacques et al. [23] reported that child users were afraid of getting "stuck in the headset" and of seeing something "scary" like in a "horror movie". Another trial [11] did not report on their assessment of adverse effects during VRET intervention.

\section{Sessions, attrition, and treatment response}

The number of treatment sessions ranged between 5 and 8 sessions in most studies. There was only one study [11] with a single session covering $90 \mathrm{~min}$. The duration of sessions in the other studies varied from 20-40 min [10, 21] up to $60 \mathrm{~min}$ [23]. Most studies reported a minimal loss of participants between preand posttreatment. However, the study by Servera et al. [21] had a higher attrition rate with a final sample of only 6 patients (initially, 37 patients were selected, 10 were randomized and started treatment), who were treated by nonexpert students. Moreover, the authors report that 2 patients in the final sample did not respond to the treatment at all. 
Fig. 2 Risk of bias assessment [10, 11, 21, 23]. + low risk of bias (green), $+/-$ moderate risk of bias (yellow), - high risk of bias (red)

\begin{tabular}{lcccc} 
& $\begin{array}{c}\text { Random- } \\
\text { ization }\end{array}$ & $\begin{array}{c}\text { Selection } \\
\text { Bias }\end{array}$ & $\begin{array}{c}\text { Confounding } \\
\text { Bias }\end{array}$ & $\begin{array}{c}\text { Measurement } \\
\text { Bias }\end{array}$ \\
\hline Gutiérrez-Maldonado et al. (2009) & $+/-$ & + & $+/-$ & + \\
St-Jacques et al. (2010) & $+/-$ & $+/-$ & + & + \\
Kahlon et al. (2019) & & $+/-$ & + & + \\
Servera et al. (2019) & & - & $+/-$ & + \\
\hline
\end{tabular}

\section{Feasibility studies}

There was only one feasibility study [19] without an evaluation of the treatment, but instead assessing differences between adolescents with and without SAD regarding subjective units of distress (SUDs) when exposed to different virtual environments. This study concludes that VR environments simulating interpersonal interactions such as public speaking or visiting a party are able to provoke specific reactions of distress as well as acceptable levels of presence; the latter has previously been defined as an experience of nonmediation and a resulting sense of actually being there in the artificial environment (see Lombard and Ditton [17] for details). Accordingly, the participating adolescents with SAD stated a good acceptability of VR in their post-debriefing interview and described the simulations as "real" or "normal". Hence, the authors concluded that good acceptability, high presence and higher levels of distress during the scenario demonstrated the suitability of VR for treating SAD patients.

\section{Discussion}

Based on the lack of research syntheses regarding the use of VRET in children and adolescents with anxiety disorders, the current systematic review set out to provide an overview of the existing literature. The search yielded only two RCTs, two pre-post evaluation studies, and one feasibility study. Preliminary results support the notion that VRET may constitute an effective treatment not only in adults (see Carl et al. [5]), but also in children and adolescents: one study showed better treatment outcomes than WL controls [10], another found a comparable reduction of symptom severity in VRET and IVE [23]. Similarly, both evaluation studies $[11,21]$ reported considerable improvements in key symptoms posttreatment, and the feasibility study [19] concluded that VRET is feasible in adolescents with SAD.

Despite these encouraging results, research on VRET in children and adolescents with anxiety disorders is still scarce at best. More studies are needed, in particular RCTs, to support the preliminary finding that VRET may indeed be efficacious in younger populations. Also, the current evidence focuses mainly on specific phobias in children and adolescents (i.e., school phobia, arachnophobia, fear of darkness) and only marginally considers SAD. In comparison, no studies were found on the use of VRET in young patients with panic disorders or with PTSD. Particularly in light of the considerably high lifetime prevalence of PTSD among children and adolescents [18], VRET may provide a useful means of trauma treatment. As demonstrated by a recent meta-analysis [16], VRET already shows promising results compared to other treatments in adult populations.

Overall, generalization across different age groups and developmental stages are difficult or even impossible, particularly when considering a technologybased treatment method such as VR. For example, StJacques et al. [23] recorded adverse effects which had not previously been observed in adult samples using VR. Some of their participants reported they were afraid of the virtual environment and feared getting "stuck in the headset", a finding which the authors discuss to be possibly related to the fact that children-due to their still developing ability to think abstractly-may not reflect in the same way on VR as adults who may more readily arrive at the estimation that virtual stimuli are less threatening than their in vivo counterpart. Furthermore, children's motivation to use VR (see St-Jacques et al. [23]) may differ substantially from the motivation observed in adults, who have generally been found to be more willing to choose exposure to virtual stimuli over in vivo exposure [9]. Also, negative effects of VRET such as cybersickness may show age-related patterns. For instance, it has previously been observed that older adults suffer from more severe cybersickness symptoms than younger users of VR [2].

In sum, however, additional evidence is needed to learn more about specific needs and problems with VRET in children and adolescents. Especially, motivational factors should be reflected with great care and put in relation with developmental stages as well as according cognitive capacities (e.g., Piaget [20]). Therefore, age-specific effects regarding a potential selective efficacy-particularly in younger cohorts-need to be investigated in future studies (Servera et al. [21]).

Generally, the potential of VR in treating children and adolescents with anxiety disorders is contrasted by a considerable lack of RCTs. Results of the current review suggest a potential benefit of using VRET in younger cohorts and clearly call for more evidence to support this promising field of application.

Funding Open access funding provided by Medical University of Vienna.

Conflict of interest O.D. Kothgassner and A. Felnhofer declare that they have no competing interests. 
Open Access This article is licensed under a Creative Commons Attribution 4.0 International License, which permits use, sharing, adaptation, distribution and reproduction in any medium or format, as long as you give appropriate credit to the original author(s) and the source, provide a link to the Creative Commons licence, and indicate if changes were made. The images or other third party material in this article are included in the article's Creative Commons licence, unless indicated otherwise in a credit line to the material. If material is not included in the article's Creative Commons licence and your intended use is not permitted by statutory regulation or exceeds the permitted use, you will need to obtain permission directly from the copyright holder. To view a copy of this licence, visit http://creativecommons.org/licenses/by/4.0/.

\section{References}

1. American Psychological Association. Clinical practice guideline for the treatment of posttraumatic stress disorder (PTSD). 2017. https://www.apa.org/ptsd-guideline/ptsd. pdf. Accessed 30 Jan 2020.

2. Arns LL, Cerney MM. The relationship between age and incidence of cybersickness among immersive environment users. IEEE Proceedings. VR 2005. Virtual Reality, 2005. 2005. pp. 267-8.

3. APA Presidential Task Force on Evidence-Based Practice. Evidence-based practice in psychology. Am Psychol. 2006;61:271-85.

4. Bandelow B, Lichte T, Rudolf S, Wiltink J, Beutel M. S3Leitlinie: Angststörungen. Berlin, Heidelberg, New York: Springer; 2015.

5. Carl E, Stein AT, Levihn-Coon A, Pogue JR, Rothbaum B, Emmelkamp P, et al. Virtual reality exposure therapy for anxiety and related disorders: A meta-analysis of randomized controlled trials. JAnxiety Disord. 2019;61:27-36.

6. Felnhofer A, Kafka JX, Hlavacs H, Beutl L, Kryspin-Exner I, Kothgassner OD. Meeting others virtually in a day-today setting: Investigating social avoidance and prosocial behavior towards avatars and agents. Comput Human Behav. 2018;80:399-406.

7. Felnhofer A, Hlavacs H, Beutl L, Kryspin-Exner I, Kothgassner OD. Physical presence, social presence, and anxiety in participants with social anxiety disorder during virtual cue exposure. Cyberpsychol Behav Soc Netw. 2019;22(1):46-50.

8. FoaEB, KozakMJ.Emotional processing offear: exposure to corrective information. Psychol Bull. 1986;99(1):20-35.

9. Garcia-Palacios A, Botella C, Hoffman H, Fabregat S. Comparing acceptance and refusal rates of virtual reality exposure vs. in vivo exposure by patients with specific phobias. Cyberpsychol Behav. 2007;10(5):722-4.

10. Gutiérrez-Maldonado J, Magallón-Neri E, Rus-Calafell M, Peñaloza-Salazar C. Virtual reality exposure therapy for school phobia. Anu Psicol. 2009;40(2):223-36. study included in the review.

11. Kahlon S, Lindner P, Nordgreen T. Virtual reality exposure therapy for adolescents with fear of public speaking: a nonrandomized feasibility and pilot study. Child Adolesc Psychiatry Ment Health. 2019;13(1):1-10. study included in the review.

12. Kessler RC, Berglund P, Demler O, Jin R, Merikangas KR, Walters EE. Lifetime prevalence and age-of-onset distributions of DSM-IV disorders in the national comorbidity survey replication. Arch Gen Psychiatry. 2005;62(6):593-602.

13. Kothgassner OD, Felnhofer A, Hlavacs H, Beutl L, Palme R, Kryspin-Exner I, et al. Salivary cortisol and cardiovascular reactivity to a public speaking task in a virtual and real-life environment. Comput Human Behav. 2016;62:124-35.

14. Kothgassner OD, Griesinger M, Kettner K, Wayan K, VölklKernstock S, Hlavacs H, et al. Real-life prosocial behavior decreases after being socially excluded by avatars, not agents. Comput Human Behav. 2017;70:261-9.

15. Kothgassner OD, Goreis A, Kafka JX, Kaufmann M, Atteneder $\mathrm{K}$, et al. Virtual social support buffers stress response: An experimental comparison of real-life and virtual support prior to a social stressor. J Behav Ther Exp Psychiatry. 2019;63:57-65.

16. Kothgassner OD, Goreis A, Kafka JX, Van Eickels RL, Plener PL, Felnhofer A. Virtual reality exposure therapy for posttraumatic stress disorder (PTSD): a meta-analysis. EurJPsychotraumatol. 2019;10(1):1654782.

17. Lombard M, Ditton T. At the heart of it all: The concept of presence. JComput Mediat Commun. 1997;3(2):JCMC321.

18. Meiser-Stedman R, Smith P, Yule W, Glucksman E, Dalgleish T. Posttraumatic stress disorder in young children three years post-trauma: Prevalence and longitudinal predictors. JClin Psychiatry. 2017;78(3):334-9.

19. Parrish DE, Oxhandler HK, Duron JF, Swank P, Bordnick P. Feasibility of virtual reality environments for adolescent socialanxietydisorder. ResSocWorkPract. 2016;26(7):825-35.

20. Piaget J. The psychology of the child. New York: Basic Books; 1972.

21. Servera M, Sáez B, Mir JMG. Feasibility of a virtual reality program to treat children with fear of darkness with nonexpert therapists. Revista de Psicología Clínica con Ninos y Adolescentes. 2019. studyincluded in the review.

22. Skrivanek C, Marte E, Winds K, Thun-Hohenstein L, Plattner B.Patterns of psychopathology and psychosocialbackground of patients at first presentation at the child and adolescent psychiatric outpatient department of the University Clinic Salzburg. Neuropsychiatrie. 2019;33(3):151-9.

23. St-Jacques J, Bouchard S, Bélanger C. Is virtual reality effective to motivate and raise interest in phobic children toward therapy? A clinical trial study of in vivo with in virtuo versus in vivo only treatment exposure. J Clin Psychiatry. 2010;71(7):924-31. study included in the review.

24. Owens DK, Lohr KN, Atkins D, Treadwell JR, Reston JT, Bass EB, et al. AHRQ series paper 5: grading the strength of a body of evidence when comparing medical interventions-Agency for Healthcare Research and Quality and the Effective Health-Care Program. J Clin Epidemiol. 2010;63:513-23. https://doi.org/10.1016/j.jclinepi.2009. 03.009 .

25. Viswanathan M, Patnode CD, Berkman ND, Bass EB, Chang S, Hartling L, et al. Recommendations for assessing the risk of bias in systematic reviews of health-care interventions. JClin Epidemiol. 2018;97:26-34.

26. Wagner G, Zeiler M, Waldherr K, Philipp J, Truttmann S, Dür W, et al. Mental health problems in Austrian adolescents: a nationwide, two-stage epidemiological study applying DSM-5 criteria. Eur Child Adolesc Psychiatry. 2017;26(12):1483-99.

27. Wang Z, Whiteside SP, Sim L, Farah W, Morrow AS, Alsawas $M$, et al. Comparative effectiveness and safety of cognitive behavioral therapy and pharmacotherapy for childhood anxiety disorders: a systematic review and metaanalysis. JAMA Pediatr. 2017;171(11):1049-56.

28. Zeiler M, Wagner G, Philipp J, Nitsch M, Truttmann S, Dür W, et al. The Mental Health in Austrian Teenagers (MHAT) Study: design, methodology, description of study population. Neuropsychiatrie. 2018;32(3):121-32.

29. Zimmer P, Buttlar B, Halbeisen G, Walther E, Domes G. Virtually stressed? A refined virtual reality adaptation of 
the Trier Social Stress Test (TSST) induces robust endocrine responses. Psychoneuroendocrinology. 2019;101:186-92.
Publisher's Note Springer Nature remains neutral with regard to jurisdictional claims in published maps and institutional affiliations. 